\title{
The Global Transformation
}

of Belly Dancing:

A Cross-Cultural Investigation

of Counter-Hegemonic Responses

Authors' contribution:

A) conception and design of the study

B) acquisition of data

C) analysis and interpretation of data

D) manuscript preparation

E) obtaining funding

\author{
Ashley M. Popp ${ }^{1 \text { A-E }}$, Chia-Ju Yen ${ }^{\text {A-E }}$ \\ ${ }^{1}$ North Central College, USA \\ ${ }^{2}$ National Taiwan Sport University, Taiwan
}

ABSTRACT

The first part of this study, explored by Ashley Popp, presents an investigation into a relatively unexamined area of physical education: an analysis of a transcultural phenomenon in the history of dance. Data has been collected from primary sources and archival evidence to assess competing ideologies inherent in the transformation of a particular art form. In the analysis of the cultural migration through which belly dance was transferred from the Middle East to the United States, an adaptive reaction to the hegemonic relationships of culture, race, gender, and class has been observed. Beyond performance aesthetics, links have been made between the act of belly dancing and the building of women's self-esteem, as researched by Chia-Ju Yen. The main purpose of her study was to explore how facial burn patients cope with disfigurement and the unfriendly attitudes of others, and examines the alteration of body image via inspiration provided by the performance of belly dance. This research was conducted from the perspective of an anthropologically thickdescription research method, and a case study was performed using in-depth interviews, including narratives by a woman who had suffered facial injuries. The results of the research showed that through family support, hard work and a decisive and studious personality, the patient was able to cope with the discriminatory attitude of others. The performance of belly dance not only made her emphasize her body, but also enriched her life.

KEYWORDS belly dance, belly, dance, transatlantic, hegemonic theory, transition, social adaptation, social therapy, cultural evolution, history, art, physical education, cultural migration, American Cabaret, American Tribal, feminism, cross-cultural, self-esteem, burn victims, disfigurement

When embarking on the analysis of any topic, it is important that one have a fairly strong foundation of background knowledge on the subject. This is a bit of a challenge when questioning the origin of the danse $d u$ ventre or, as more commonly known in the United States, belly dance. This academic inquiry requires a far reach into the often subjective oral and written history of both American and international peoples. This subjectivity, understandably, both allows for and requires the acceptance of the possibility of lore and opinion as relevant information. Though these sources of information might not be complete, they allow for the estimation of (what one hopes would be) prominent values during a given period of history. 
A factor that must be considered when calculating the history of any dance is the probability that a singular form cannot be traced through any one particular culture. It is much more likely that multiple separate cultures simultaneously developed and implemented similar ritualistic or recreational dances. There is documentation throughout history of comparable activities being performed in multiple different cultures with only slight variations between these cultures. An example of this would be the male populations of many ancient civilizations taking part in preparatory war or hunting dances. Through this transcultural phenomenon, men played out symbolic movements and humored cultural superstitions relevant to their roles in their tribe. A parallel from this assumption can also be drawn in the development of belly dance. Though their roles from differing cultures varied, women performing symbolic dances were fulfilling their societal roles.

The history of dance is extensive: it was first documented, inadvertently, around 40,000 B.C. It was in this "post glacial period" that the imprint of a woman's dancing feet [was] preserved in sand... archeologists called this the Woman's Dance of the Congre (Gioseffi 1980, p. 30). As history went on, the documentation of the art grew to include dancers depicted in cave paintings, confirmed on papyrus scripts, and eventually became organized and specific with the creation of genres such as ballet in 1498. When it comes to the origination of belly dance, an observer must completely dispel any preconceived notions that they may have in regards to the sound, look, and concepts that surround the art. This is because the recognizable belly dance of today is something that has been created very recently in terms of the history of the dance (this idea will be explained in more depth further into this analysis).

It is human nature to prescribe the past to an idea, object, or art so that it can be understood more completely by the recipient of the subject. For instance, in belly dance this has led to numerous amusing, romantic, and possibly false accounts of both its history and purpose, with these stories serving the role of an explanatory function. These stories range from belly dance serving as a means of sexual competition among a sultan's multiple wives, a demonstration of the sexual expertise of a courtesan, or as a representation and worship of a culture-specific goddess. One theory in particular, which is the expertise of dance historian Daniela Gioseffi, describes belly dance as a re-enactment of ancient birth rite. Gioseffi claims that supporting evidence for her theory lies in the traditional "floor work" portion of a dancer's routine, where the performer drops to her knees and undulates her torso. Gioseffi connects this movement to the practice of primitive women giving birth from a kneeling or squatting position and believes this modern day act "is actually a remnant of the ancient birth mime" (Gioseffi 1980, p. 28).

It is possible that one, if not multiple, of these stories are true. Unfortunately, despite directed research, it seems impossible to locate any single story that has not been tainted with the ideals, perceptions, or images of Western culture. Andrea Deagon, a dance scholar, presents an interesting viewpoint in terms of the subjectivity of the history of this art. She notes the tendency of modern peoples to think of the past as "simple", and to consequently look for simple origins of historical ideas, such as a "one-sentence explanation" of the origin of a dance. However, as she so ironically describes it, "Any simple story is more likely myth than truth" (Deagon 1998). Regardless of our intentions, our perceptions of past societies (especially when in direct comparison with our own) affect the popular histories that come forth.

Luckily, the climate in the United States before and around the time of the arrival of belly dance has been well documented. Concepts including the "Manifest Destiny" and other such ethnocentric ideas had been a mainstream mentality in the United States dating back to approximately 1839. This cultural characteristic was somewhat ironic considering America itself did not have a sound identity; there was an almost constant tension between the industrial north and the plantation dominated south. In the mid- to late 1800s, with the coming of the Gilded Age, the American population began to expand, which provided for "a climate where sports ... developed and flourished" (Gems 2009, p. 27). This climate was predominantly positive for white Anglo-Saxon males. The attempts of this dominant group to spread ideas to other races and classes characterized the Progressive Era, which started in the last quarter of the 1800s. Americans living in this period were victims of social tensions between the idealism of the active advocates of progressivism and the corrupt world of wealthy politicians, businessmen, and promoters of Social Darwinism. It is in the 
beginning of the Progressive Era that belly dance made its debut in the lives of Americans and their tumultuous culture.

Belly dancing has been known by a multitude of descriptions: Danse oriental, danse du ventre, the stomach dance, Beledi dancing, the Dance of the Almees, the Dance of the Awalem, Ghawazee dancing, Eastern dancing, Middle Eastern Dancing, Near Eastern Dance, Egyptian or Moroccan or Arabic or Persian dance, ancient Etruscan dancing, the Egyptian Morisco...(Gioseffi 1980, p. 17).

This etymology directly suggests the diverse and multicultural origins of the dance. However, it was not until its transition into American culture that this art came to be known as "belly dance", which was supposedly dubbed by American soldiers who frequented Middle Eastern cabarets (Gioseffi 1980, p. 34). These titles, though not direct translations, are also interchangeable with raqs sharqi, which is the Arabic term preferred by many practitioners. They prefer this term because it gives "the genre more respectability and diminish[es] its overt sexual references and emphasize[s] what they perceive as its artistic and aesthetic aspects" (Shay 2008, p. 125). The need for this declaration of decency has been created through more than a century of condescension towards and manipulation of the dance by American society.

The first documented appearance of belly dance in the United States was in 1876 when dancers performed at Philadelphia's Centennial Exposition "without incident" (Gioseffi 1980, p. 46). However, it was not until the World's Columbian Exposition in Chicago, Illinois, that dancers from the East began to attract the attention of American society and media. This 1893 exhibition has remained "the most writtenabout event of its kind ... long before the mass media systems of the present day" (Carlton 1994, p. 7). There were over 50,000 demonstrations showcased in Chicago's Jackson Park, one of the most popular being the "Streets of Cairo" display on the Midway where the "dancing girls in the Algerian and Egyptian theatres drew the most attention ... for their specialty the danse $d u$ ventre" (Badger 1979, pp. 107-108). It was through this venue that belly dance gained its fame and began its long-term affair with the American public. The "Streets of Cairo" attraction included women dancing in oriental costuming and performing odd yet entertaining tricks. For example, a dancer "After executing a series of contortions to the quickening measure of Egyptian music ... grips a chair between her teeth," which she used to hold the chair above her head while spinning around to "dizzy music" (St. Louis 1904, p. 268).

These Ouled Nails (fully clothed) dancers were presented at the Midway of the exhibition, which contained exhibits "from around the world ... to show the progress and development of human civilization" (Carlton 1994, p. 11). However, the capitalistic mindset of the event's organizers jeopardized the event's alleged purpose: a truly scientific and educational endeavor. Sal Bloom, the promoter who arranged for the Middle Eastern dancers to perform at the World's Columbian Exposition, was quoted as saying, "When the public learned that the literal translation [of danse du ventre] was 'belly dance' they delightedly concluded that it must be salacious and immoral. The crowds poured in. I had a gold mine" (Badger 1979, p. 108). This event demonstrated a pattern of the "West's desire to subvert, dominate and exploit the Orient for its own purposes" (Carlton 1994, p. 19), which will be discussed in greater detail further into this analysis.

Not only did the exhibit present opportunities for exploitation by potential investors and moneyhungry promoters, it also presented exotic cultures in such a way as to affirm the already racist and colonialist views that were held by many of the American population. Many promoters, organizers, and scientists "masqueraded in a cloak of philanthropy" as they pursued their social and financial goals (Shay 2008, p. 54). As observed by historian Paul Greenhalgh in 1988, the "public could see... and feel in a real sense that they (the colonial peoples) belonged to them" (Carlton 1994, p. 13). Instead of fulfilling the Midway's supposed intention of showing progression of the human race, many exhibits were "designed to demonstrate the primitiveness of nonwhite (non-European) cultures so that there would be no confusion about who was and who was not inherently a true, 'civilized' American" (Badger 1979, p. 105). By the end of the 1893 World's Columbian Exposition millions (estimated to be approximately 5-10\% of the American population) of spectators had experienced the attractions presented in Chicago. The widespread press that 
was generated by this event paved the way for the spread of belly dance as a form of controversial entertainment in the United States.

One cannot mention the introduction of belly dance at the 1893 World's Columbian Exposition without making reference to one particularly legendary dancer. As noted by a historical article in the Chicago Tribune, "ask the average American what he knows about the Midway of $1893 \ldots$ and he will instantly answer, 'Little Egypt"” (The Myth of Little Egypt, p. 14). This Little Egypt character was supposedly the first popular and recognizable belly dancer in the United States. This celebrity status meant much more when assigned to an individual in that time period when performers did not just dance, they "generally sang and performed acrobatic feats, and sometimes exhibited other talents" (Shay 2008, p. 136). Though these women were multitalented, their profession carried an assumption of less than moral activities. Thus, "women who pursued the performance of Oriental dance at the turn of the century ... did it for money", not for fame or popularity (Shay 2008, p. 141). The reputation one gained from performing the dance was too large a result for the mere gratification of the performance alone. However, contrary to the memories of exhibition attendees as stated above, the Chicago Tribune reported on May 7, 1942, that "there is no evidence on the Midway's official advertising sheet that Little Egypt ever existed" (The Myth of Little Egypt, p. 14). Despite the fact that there is no evidence of this person ever performing at the Midway, the idea of this person, and her name in particular, would eventually become synonymous with belly dancing. The concept would also be frequently imitated: "it appears there were so many Little Egypts that the name was ... well on its way to becoming generic for this type of entertainer" (Carlton 1994, p. 61).

In accordance with this information, the name "Little Egypt" gained the most notoriety for a publicized and questionably salacious event in 1897 that was coined "The Awful Seeley Dinner." Even Sol Bloom, the promoter of the Middle Eastern exhibits at the 1893 World's Columbian Exposition, credited this situation as "the incident that popularized the Little Egypt character" (Carlton 1994, p. 65). This affair, in a nutshell, was the questionable act of Mr. Herbert Seeley engaging a dancer named Little Egypt to perform for a group of artists "two numbers, a dance and a pose" (Carlton 1994, p. 65) that was stumbled upon by police Captain Chapman of New York City. These "artists" consisted of a group of both married and unmarried men, many of whom were not artists by definition. The loosely defined course of events that evening caused quite a stirring of judgmental curiosity in the surrounding community, and many "inferred that Herbert Seeley planned for a naked female to entertain a roomful of men" (Carlton 1994, p. 65).

The culmination of the fervor surrounding this event as the appearance of Little Egypt as a witness at the trial of Mr. Seeley with regards to her questionable employment. "Great things were expected" from the testimony from a dancer of such questionable morals and throngs of people appeared in the hopes of seeing evidence related to the content of the night in question. However, "the evidence was not as 'hot' as anticipated" since Little Egypt, who testified under the name of Ashea Waba, spoke without producing substantial visual aids ("Little Egypt" Tells of the Party, p. 4). Much of the interest surrounding the event diminished after her testimony and "the spectators were visibly disappointed that they had seen no exhibition of the couchee-couchee dance" ("Little Egypt" Tells of the Party, p. 4).

At a time when "the exposure of a bare foot was considered indecent" (Shay 2008, p. 56), the unfolding of this incident was understandably a massive controversy. It was, however, not the only incident of its kind. In New York City, as early as 1893 girls were arrested for "giving an exhibition of the danse du ventre at the Grand Central Palace" and the announcement of their appearance in court "attracted a large attendance" (No More Midway Dancing). This sort of publicity had negative consequences on the American views of the characteristics and subsequent intent of the dance form. Events like the widely publicized "Awful Seeley Dinner" made it acceptable (and practically politically correct) for the American population to pass quick and harsh judgments on both the dance and those who performed it.

There also lies a deeper, somewhat convoluted social paradox at work within these occurrences. Although the American people blatantly disapproved of what belly dance represented, a significant portion of the culture also was wildly fascinated with what they deemed to be elements of "Oriental" culture. This 
fascination with exotic effects represented "an integral part in popular culture, particularly from the period 1890-1930" (Shay 2008, p. 58). This paradoxical desire of American society resulted in the popularity of many Oriental themed shows, such as the opera Salome and a play called The Silly Dinner, which was a spoof on the Seeley dinner scandal. This explains why a number of Little Egypts started varying in ethnicity, as various American belly dancers "began popping up as fast as an actress could wrap a fringed shawl around her hips" (Carlton 1994, p. 69).

This abundance of dancers and America's blossoming interest in the art can be attributed to the population's fascination with what they judged to be that of "oriental" origins. This heightened interest in Orientalism started around the time of Chicago's 1893 World's Columbian Exposition and was embodied by "fanciful cigarette card and postcard depictions of harem women" and "orientalist-style nudes" which were usually displayed at neighborhood saloons (Carlton 1994, p. 19). However, it is interesting (but, contextually speaking, not surprising) that the women in these pictures were "a nineteenth century ideal of Caucasian beauty ... posed in Arab garb" (Carlton 1994, p. 17). This fact brings to light, once again, the paradoxical nature of American society's fascination with items of Middle Eastern origin - they both admired them and scorned them. Whether depicted in photographs or by live performances, "America categorized Arabs as an unacceptable class of non-whites, and thus their dance was regarded with suspicion as lascivious, and more importantly, as a cultural production of the "lower'" classes (Shay 2008, p. 128). Despite these widespread feelings about Arab culture, the fascination with the Orient persisted. These two contradicting opinions demanded that American belly dancers find a proverbial "middle ground" on which to base their dances.

What American belly dancers came to depict "gave the upper class what they had been looking for ... a lithe, slim Orientalist vision, a bejeweled body aching for $\sin$ " (Carlton 1994, p. 64). The positive reception of Oriental-themed performances allowed female viewers to "create their own sexual imaginaries through the highly Orientalist images ... with its white western heroine" (Shay 2008, p. 64). These widely adored visions were created by originators of American belly dance, such as Maud Allen and Ruth St. Denis. Both the dances performed and the costumes adapted and utilized by these women were something distinctly new to belly dance. Their interpretation was massively influenced by American society and could easily fall into the description of a balancing act: these women had to strategically negotiate and adjust their belly dancing identities in order to please American audiences, which were vastly effected by an "austere religious climate [that] produced deep choreophobic reactions" (Shay 2008, p. 67). Dancers attempted to meet the ideals of society by making an adequate departure from the original Middle Eastern form of belly dance in order to "distance themselves from the actual practices of Middle Eastern and Asian natives," which were perceived as lowly (Shay 2008, p. 139), while still maintaining the Oriental aspects of the dance that were, to Americans, "exotic in an interesting and attractive way" (Shay 2008, p. 138). These dancers successfully created a generalized version of the dance rather than showcasing any culturally identifiable specifics, in essence conveying only "some faint whiff of the exotic Orient" (Shay 2008, p. 61). Dance scholar Anthony Shay suggests that these dancers "made a conceptual break with past practices and created the new genre that we today call belly dance" (Shay 2008, p. 134).

This American adaptation of the initial origins and core intentions of this art can be considered the first tangible influence of hegemony on the concept and act of belly dance. Mainstream American morality and ethnocentrism at the time would not accept traditional Middle Eastern cultural displays such as belly dance. Dancers therefore had the choice to accept, reject, or adapt their art in order to comply with American standards of the time. Authenticity, at this crucial transitional point in the dance's history, was not important. These innovators of American belly dance, whether knowingly or intuitively, made significant changes to a foreign dance that in essence created something that was unique. This new style has since been known as American Cabaret style. They had created a variant art form that expressly complied with the preset standards of its host culture.

This adjustment served to eliminate the primitive and foreign connotations that followed the dance; however, many Americans still held very biased views about what performances of belly dance communicated. When comparing an Arabic culture with that of the United States, there are some innate 
differences in the ways in which art is viewed. For example, in the majority of instances, "Americans ... expect semantic intent in art", which points to the most rational and literal presumptions (Shay \& SellersYoung 2005, p. 44). This means that when Americans see revealed skin, shimmying shoulders and hips and flowing movements, they tend to assume seductive intentions. This interpretation of the dance is much different than that within the context of the Middle East. In its original social settings, belly dance was seen as a community event that was usually initiated at close-knit social gatherings. It is somewhat like a social game, described as "light hearted play", which is "neither programmatic nor literal" to the performer or her/his audience (Shay \& Sellers-Young 2005, p. 41). Dancers would playfully "flirt" with family members in jest, but would never exhibit this sort of play with a potential love interest.

Between the geographical origin of belly dance and the growing interest in the United States, there was an obvious disconnect of ideas and frames through which each respective culture viewed the world. Whether intentionally or not, the innovative American belly dancers felt this difference in sentiments and reacted by creating an Americanized version of the dance including the sexualized "iconic bikini-like costume" that became popular in the early 1900s (Shay 2008, p. 134). Though these American dancers made departures from authentic Middle Eastern details, they often maintained public acceptability by emphasizing the spiritual aspect of the dance. This strategy, whether rooted in truth or not, allowed them to "negotiate the slippery slope of appearing in public scantily clad and performing sensual movements" that were socially ascribed with connotations of prostitution. The evolution of the dance, in this specific time period, was also affected by the lack of formal education surrounding the movements and terminology. Many of the American dancers learned their art by watching what other performers did in Middle Eastern themed restaurants and imitating such movements. "Learning on the job" and the lack of focused learning meant that "many of the movements of belly dance could be acquired in a relatively short time, sometimes within a few weeks" (Shay 2008, p. 144), which is historically unheard of in the terms of professional dance.

The evolution of belly dance catered specifically to American tastes at the turn of the century, and these changes led to frustration within Middle Eastern cultures. Alterations that were made to the dance, as hypothesized earlier, created a new westernized genre of dance, which was exclusive to the innovative American dancers. This gave American society even more reason to view native dancers of Oriental descent with distaste; the performance of belly dance by any native was there forth "fixed in the public mind as vulgar" (Shay 2008, p. 61) in comparison to the westernized version. Even in the early 1900s the westernized version of the dance made its way to back to its region of origin, Egypt in particular. There, performances of the transformed dance led to feelings of aversion among natives who were infuriated with the ignorant domination of their social dance and its underlying meanings. As pointed out by dance historian Daniela Gioseffi 1980, this resentment was recorded in the writings of a Middle Eastern native (which was translated to English in 1923):

"Thus in Cairo one evening I saw, with sick incredulous eyes, one of our most sacred dances degraded into bestiality horrible and revolting ... the spirit of the occident had touched this holy dance, and it became the horrible 'danse du ventre,' the 'hoochie-koochie'...' (Gioseffi 1980, p. 34).

These feelings of animosity within the Mideast were exposed by the adaptation of the dance and were directly attributable to the "misunderstanding and ignorance of underlying cultural values" (Shay \& SellersYoung 2005, p. 46).

The workings of social hegemony dictated the westernization of belly dance, and would continue to do so throughout the remainder of the century. American popular culture took hold of the art, and was the main force in the continual evolution of the dance from the 1930s through the 1950s. One common method of learning for American dancers was mimicking the dancers of old Middle Eastern themed films. It is this medium through which belly dance "was further corrupted ... as an oriental dance in Hollywood's biblical epics and Roman spectacles" (Gioseffi 1980, p. 39). This corruption refers to the sensationalized and sexualized manner in which belly dancers were presented, most often dressed in minimal yet flashy costuming, and portrayed with contradicting combinations of naive vulnerability and licentiousness. This 
represented a vast departure from the original form of the dance, as well as from the styles of the dancers who had exported the dance of their native lands. The longer that belly dance stayed and evolved in the United States, the more it became a dance that was distinct from its origins. Although belly dance was undergoing major changes between the 1920s and 1950s, it seemed to fall out of interest in Middle Eastern communities, Egypt in particular. According to scholar Anthony Shay, this lack of attentiveness to the dance in Egypt resulted in the "widespread and erroneous concept of a dance tradition [that has] an unbroken line with the past" (Shay 2008, p. 131). Americans, with our relatively short history, seem to be drawn to cultural concepts and customs that transcend long periods of time. We therefore assume that what we know of belly dance is something that was passed down from authentic Middle Eastern practitioners, as this is how we like our stories to be told. However, this obviously is not the case. Necessary reactions to hegemonic forces in the United States created a dance that, though discernable as something remotely related, has practically no identical characteristics or purposes of the original dance.

Hollywood's representation of dancers made neither characters that were identifiable nor relatable to women; instead it created merely beautiful and desirable personas. Though this worked to serve the purpose of the stories being told, American women did not particularly connect to these characters, as they did not exhibit any identifiably American traits. An oriental character that was substantially relatable to American women would not come along until the mid-1960s, when I Dream of Jeannie began airing on NBC. This popular show provided female audiences with a character who depicted Middle Eastern folklore along with stereotypical distinctions of middle class American suburbia. Jeannie was accessible and easier to relate to, which "made the harem girl and her quintessential belly dance safe for the hordes of middle class white women escaping the humdrum life of suburbia..." (Shay 2008, p. 127). It was this show and its depiction of a socially acceptable, though unrealistic, oriental character that would influence many women to take part in the fitness and belly dance revolution that swept the 1970s. The women who participated in these fitness classes were often suburban housewives who sought not only fitness but also a behavioral vacation to an exotic mindset.

As these changes continually progressed, the disapproval of Arab-Americans grew in turn. They were generally dissatisfied with the initial adaptations to the dance, and eventually they started to feel culturally misrepresented by the American version of their culture. The majority of this population felt "that American dancers misrepresent[ed] their culture though orientalist images of sexuality" (Shay 2008, p. 146). The development of these negative feelings by Arab-Americans was almost simultaneous to a similar reaction in Egypt. The westernization of the dance had slowly made its way to the Middle East, and it wasn't long before native dancers starting adopting the new stylized dance to please their audiences and to have a competitive advantage over other dancers. The Egyptian government did not like these "shamefully meaningless" performances that were misrepresenting their native culture. The country attempted to take control of the situation in the mid-1960s when they mandated that all 'professional' dancers attend an approved belly dance school. The purpose of this school was to "introduce 'meaningful' motions to the belly dance... change the name of the art to "oriental dance' [and to]... 'cleanse and polish [the] movements"' of the dancers ("Belly Dancers Told..."). These provisions even had extreme requisites such as disallowing blonde students and changing costumes to cover the navel and ankles. It seems to be a legitimate inference that this legislation made by the Egyptian government was an attempt to reverse the negative changes that the West had made to their dance. The evolution of the dance served to adapt to hegemonic forces in the United States; the evolved dynamics, however, served to reject the hegemonic ideals set forth in Middle Eastern cultures.

Concurrently, American society experienced a surge of interest in fitness due to an increased desire for personal health. Many individuals were being active and seeking alternative ways to have fun while reaching their fitness goals. After being exposed to westernized ideas of belly dance in previous decades, many women began to realize that belly dance could serve as more than just a form of entertainment. This movement seemed to be borne out of a west coast mentality, and soon there were belly dance fitness classes popping up throughout the entire United States. According to dance historian Daniela Gioseffi 1980, the 
period from 1970 through 1979 marked the height of the belly dance movement in the United States. Women joined classes and clubs for motives such as "the pursuit of love, spirituality ... sexual and sensual empowerment, losing weight, feeling attractive, and joining other women in an affirming activity" (Shay 2008, p. 141).

This movement was so culturally penetrating that in 1978 a national television program had specific coverage on the phenomenon: "20/20 estimate[d] that there [were] one million belly dancers in the United States" (Gioseffi 1980, p. 47). This figure identifies a level of popularity that communicates a massive conceptual departure from social norms of the early 19th century. The sheer number of men and women involved in belly dance made a powerful statement about the societal acceptance of a once frowned upon art form. One must keep in mind, however, that the cultural embrace manifested by Americans in the 1970s was in relation to a dance that was nothing of its original form or purpose. Instead, through hegemonic reactions, previous dancers had used variations of belly dance as a launching pad for the well-being and esteem of future generations of American women. It has been proposed that participation in belly dance gave a oncesuppressed population of women control over a man's gaze, which was "a way of undoing some of the damage dealt [to] the female image by Dr. Sigmund Freud and his approach to women as hysterical children" (Gioseffi 1980, p. 81). The fitness, sexual, and second wave feminist movements that occurred in the 1960s and 1970s served as a historical bloc for the social acceptance of belly dance; a degree of enlightenment was spurring on the country's recognition and fascination with the art. An article from the Chicago Tribune dated April 21, 1973, recounts three generations of women attending a class; the grandmother of the trio related the dance to a previous social fad: the Charleston. This presented not only a bonding experience for women, but also a way to boost their self-esteem: "many women who began to take the classes as a form of exercise ... soon [found] themselves professional dancers" (Yates 1971). In this way, professional American belly dancers were also laying the foundations for future women to make personal transformations and overcome the superficial issues of body shape and weight. Such an application can be seen in nations other than the United States as well. A specific instance with regards to the therapy of Taiwanese burn victims will be introduced further into this investigation.

While American Cabaret's popularity skyrocketed nationwide, the art began to go through its second major transformation. In the San Francisco area around 1968, Jamila Salimpour and her American Cabaret belly dance troupe were performing at a Renaissance Faire in Southern California. As her troupe grew, dancers in scant and sparkling costuming began to overrun the fairs they participated in. Eventually the rampant dancing in the streets caused the director of the faire to confront Jamila about the lack of continuity between the faire setting and the glamorous costuming of her dancers. Jamila's response to this repressive force was to create "the dance that would displace Hollywood's harem representation; an image that would correspond with the faire's natural outdoor environment and Renaissance flavor..." (Shay \& Sellers-Young 2005, p. 284). She created what we know today as American Tribal Style belly dance.

This dance had little of the sparkle and flirtatious nature of American Cabaret; instead, it was identifiable with characteristics such as "coin girdles, draped fabrics, head coverings, tattoos, with swinging hips, undulating torsos, swords, trays, pots, and water glasses" (Shay \& Sellers-Young 2005, p. 284). This dance, due to its development from a specific situational complaint, was touched by the workings of hegemonic factors on a small scale. It was not a reaction to suppressive forces of society; instead, it was developed as an adaptation in attempt to better accommodate specific audiences. This new dance did however gain popularity due to the acceptance of belly dance on a general level in the United States. The appreciation for this art allowed and encouraged open adaptation of the subgenres of the dance. Although not through the same mechanism, the tolerant attitudes in the United States in the 1960s and 1970s allowed for further evolution of belly dance that would be similar to that of a reaction to hegemonic factors. One dynamic in particular did play into the initial success of this evolution. This dynamic was the location of the most recent aspect of the dance's evolution. San Francisco and the surrounding area was "the West Coast cultural and literary site that privileged experimentation and challenged the status quo..." (Shay \& SellersYoung 2005, p. 277). 
An example of American Tribal Style's lasting success is exhibited through the formation of Fat Chance Belly Dance, a troupe of dancers that was organized by dancer Carolena Neroccio in 1987 (two decades after the creation of the alternative dance style). This troupe implemented the already established American Tribal Style, but displayed performances in a different manner with emphasis on positive relationships and community among women. The performances usually consist of three or more dancers who simultaneously improvise their dance based on visual or auditory cues from a specific leader. The dancer's attention is therefore "not on the audience's reaction to her performance, but on the interplay of cues that signify the ongoing interdependence of the tribe" (Shay \& Sellers-Young 2005, p. 291). The idea of women as a community is one that has fallen out of popularity, especially in the competitive United States, since the earlier part of the century. This concept of communal female emotional support functioned to counteract the perceptions and expectations of society on women in the 1980s that were set forth in previous decades.

Over the course of a century, belly dance has undergone many changes as society has dictated which parts of the art are acceptable, and which are not. Belly dance, unlike many other genres in dance, has exhibited qualities of a living organism that consistently grows and adapts to the environment around it. Through the years, increased tolerance by American society has "widened the perception of what constitutes belly dance and the degree of authenticity that adheres to its variegated performances" (Shay, p. 145). It is no surprise then, that belly dance has undergone yet another resurgence within the past five to ten years. It now seems to be everywhere, "taught in universities, church basements ... local studios. It is danced in museums or theatres, in street fairs, parks, at wedding parties, in living rooms, and cabarets" (Gioseffi 1980, p. 17). There have even been magazines started and circulated for the specific purpose of the enjoyment of belly dance and the creation of the "belly-gram."

On the world stage, pop entertainers such as Shakira and Beyonce have utilized belly dance to attract people to their performances. Meanwhile, famous promoter Miles Copeland has expanded his empire by creating the Belly Dance Superstars, a troupe of professional dancers who have been touring the world since 2003. The show that he organized includes dancers from multiple genres of belly dance. At performances there are "hundreds of people [who are] just hypnotized by [the spectacle]" (Stanley 2004). This cycle of popularity makes some contemporary belly dancers nervous, they consistently worry about how new audiences might perceive their art. Regardless of their fear, belly dance will likely continue its pattern of adaptation and growth: as understood and best noted by the professional dancer Shira, "I fully expect that a decade from now, the position of 'Belly Dancing' in American culture will be different from where it is today."

While belly dancing has evolved into esoteric, subcultural forms providing a greater sense of empowerment for females in the United States, Taiwanese women have utilized the more traditional form of the dance to reclaim their self-esteem, as shown in a work by Chia-ju Yen. Her autoethnographic research was directed at analyzing the utilization of belly dance as a form of therapy for women who had been traumatized by facial scarring. Her findings have been presented as follows: a woman has suffered an accident, and has lost her beauty forever; her life therefore has changed course. The face is the most visible part of the body, and is also the core of one's body image; it serves to express personal feelings. Patients who are recovering from facial surgery must cope with visible deformity, loss of function and a particular judgment placed on them by others. Because of society's general emphasis on physical attractiveness, body image alteration for such patients carries the additional burden of obvious facial disfigurement.

Recently, belly dancing has become popular in Taiwan. The sexy costumes, graceful posture and passionate music attract all kinds of women. Even female judges, with their serious demeanor in Taiwanese society, also belly danced at an end-of-year party. Many organizations have established belly dance clubs; it is even performed in local parks. The author is also a member of a belly dance club at the university at which she is employed. 
This author was affected and shocked by a picture printed in the China Time News dated January 8 , 2007, depicting facially disfigured women in a dancing parade on the streets. She wondered how they could publicly expose their scars so happily and confidently without hesitation.

Body image is a personal, comprehensive, appraisable concept of one's own body's characteristics, which include a personal view of one's body and a feeling for other people's perception of it (Zhang 2000). After seeing the above-mentioned photo, I initiated research on the body image of facially traumatized patients, performance of belly dancing and other related topics; twice I attended their performances. On site there was always a man who helped them a great deal. For example, after an outdoor performance, he put an overcoat over one of the dancers - who I came to find was his wife, Ms. Yao. I admired and was touched by the scene: after a tremendous injury, a facially traumatized female could fall in love again and enjoy a happy marriage. I was curious as to how they could overcome a visible deformity and accept each other.

A burn or trauma experience itself is frightening and is not part of the expected range of the human experience. During their prolonged hospitalization, victims face pain, helplessness, and dependence. Furthermore, they are confronted by psychological problems in terms of self-esteem and body image (Taal \& Faber 1998). Accordingly, it is difficult to get in touch with facially traumatized patients; however, the Sunshine Social Welfare Foundation (called SSWF for short in this study) gave the author a valuable chance to finally interview such a person. Ms. Yao. She represents my third informant, and gave me a warm welcome - openly revealing to me the story of her trauma and matters related to it.

The subject, Ms. Yao, age 50, was married at the early age of 16, and gave birth to a boy once a year for three years thereafter. Her injury cost her parents a lot of money, so she tried her best to overcome her facial deformity in order to get a job and raise her three children. As a result of her hard work, she succeeded in changing other people's attitude toward her and also advanced in her job from part-time employee to department head within ten years.

As a volunteer at SSWF, while practicing and performing belly dance, she felt that she had the responsibility to help and inspire other members. She was the first individual to put on a belly dance dress, and always encouraged those who struggled with their confidence. Belly dancing created new friends and, furthermore, provided new forms of body expression.

Previous research on burn injuries has focused more on medical treatment than on psychological adaptation of patients. A few cases of research are harder to qualify than the validity of so-called standard research. There is limited knowledge concerning the effect a burn injury has on an individual, furthermore one has already undergone physical and psychological changes and adaption in body image.

The study is not based solely on appearance, but also reflects certain preconceptions. It manifests our point of view, but also requires learning and transformation on the part of the researcher. The author had previously experienced belly dance performances at the workplace. In the beginning, the rapid shaking of the belly was painful yet tolerable for everyone. Different opinions about costumes arose before the performance, as members were afraid of revealing their scars publicly. What was it that erased the fear from these women? What was the origin of their self-confidence?

1. At the beginning of sudden injury

Although the support of her parents saved her life, her little children's fear of her deformity upset Ms. Yao for a long while. Before her injury, she was a full-time housewife and stayed with her children all day long. But after her injury, she became a total stranger to her children.

2. Trying to be independent by looking for a job

She ignored the opposition of her father and actively looked for a job. Because of her hard work, she performed well and overcame the obstacle of her appearance in the workplace.

3. Falling in love again

Her current husband discovered that she was a smart, diligent, and amicable lady. From my observation in watching her performance, her husband is very considerate to her and her partners. 
4. Experience of performing belly dance

As a means of encouraging other members, she continued to practice belly dance. Prior to performance, everybody hesitated to put on the sexy costumes because they revealed physical scars. As a volunteer, Ms. Yao carried the responsibility of inspiring the team. She was the first one to dress in costume with confidence. During practice, she always encouraged those with less confidence.

The damaging injury, which scarred Ms. Yao, occurred almost 30 years ago. Most memories of the event are still vivid to her, but others are not. The discussion of this topic was as follows:

1. Experience of pain and cognition of injured body image

During the interview, she seldom referenced the experience of pain. She said,

"While unconscious, I experienced many illusions, like being laid under a group of willows with a lot of patients like myself. A mild wind blew over my softly, but I didn't feel much pain. The only vivid image was that of a doctor taking a piece of skin from my right lower leg to patch the wounds, which almost killed me".

Perhaps it took quite a long time for her to remember the details of trauma and recovery. The splitting pain was only in her lower leg. The most memorable thing to her was her being treated in the hospital without dignity, which made her feel so humiliated that she refused to go back again.

Her parents tried to cover any object that could reflect her face. But she already knew about her deformed face; while she was in the hospital, she happened to drink a black-colored Chinese medicine from a bowl. It was then she said,

"When I moved the bowl close to myself, I saw my deformity in the reflection of the black liquid.

Oh! That was my face and I accepted it right away without any hesitation ... when I left the

hospital, I never went back for my facial problem. I was insensate; I am also curious as to why I was careless about my appearance then!"

I wondered how she could be so decisive at such a young age, so I called her again to ask her this question. She told me that her consciousness and awareness were dulled at the time, so she thought little about her facial trauma.

2. Work enhanced her ability and confidence

Before her injury, Ms. Yao had never worked. So when she got her first job, she worked very hard: not only to be independent but also to change others' unfriendly attitude towards her. She worked harder than anyone in the factory that employed her; almost every day she was the last one to leave the factory. Eventually she earned a substantial promotion. She also attended a computer class and graduated as valedictorian. Through this she gained not only a feeling of achievement but also built confidence from working.

\section{Confidence enough to accept new love}

Body deformities are not accepted by people easily, and could even be a reason for divorce (Hunag 2007). Consequently, it was hard to believe that Ms. Yao could get married again. Her husband's boss advised him not to fall in love with her, because his group of friends would have a hard time accepting this. Bull and Brokking (1994) stated that people tend to devalue a person with a facially traumatized spouse. Ms. Yao said "I don't care what people think; what I care about is only: does he really love me?"

Ms. Yao always downplayed other people's views and concentrated on the points of importance. Opponents of marriage to a facially traumatized person can even come from the latter's own family: Ms. Yao's brother warned her husband not to torment his sister.

\section{Belly dance enriched her life}

Dance is a rhythmic sport; it is a special, perfect game. People perform for other people vitally. Belly dance also exhibits the attractiveness and sex appeal of women, possibly helping patients to regain satisfaction in their body image. Ms. Yao showed me many photos of herself in her belly dance costume; there are some on the table, wall and refrigerator: 
"My mother told me that I enjoyed very much having photos taken of myself in those years. I also treasured myself because it had been so difficult to get my life back. Although I had been beautiful, let past be past. Now is the best time".

The experience of sport can preserve the essence of life, as Liu I Min (2005) observed:

"Sport provides the experiences of creation, depth, growth of mind and symbolization that can cohere the elements of life. To preserve one's life by sport, based on a new manner of observation, one can create a new life for oneself - a new order of life".

I quote an excerpt from Ms. Yao's blog to close this paper:

"Although we are a bunch of deformed belly dance dancers, every dancer in every performance could face the audience honestly and show her ardor for life. We may not be the best performers, but we are the bravest dancers on the stage".

Though our two efforts in research started with different intentions and describe different dimensions of a singular topic base, strong correlations can be found in the findings of each. Ashley Popp's initial historic research ended with a hypothesis regarding the ability of contemporary belly dance to increase the confidence of participants; this cultural transformation has been manifested in an evolution of original style and purpose through the relatively recent formation of American Tribal Style belly dance. This evolution challenges the classical conventions of this presumably ancient art form. This inquiry suggests that the cultural flow of belly dance retains residual cultural elements, while race, gender, and class dynamics in the United States have spawned new forms that are more conducive to alternative cultures. Chia-Ju Yen's research relating to burn victims explicitly observes this phenomenon taking place in a practical therapeutic setting, further reinforcing that these new forms have also served as an avenue through which contemporary women can build their self-esteem and potentially recover from traumatizing experiences.

\section{REFERENCES}

Badger, R.R. (1979). The Great American Fair: The World's Columbian Exposition and American Culture. Chicago: Nelson Hall.

"Belly Dancers Told: Change Your Ways" (1967). Chicago Tribune, 22 January 1967: A1. Print.

Carlton, D. (1994). Looking for Little Egypt. IDD Books.

Deagon, A. (1998)."In Search of the Origins of Dance." Habibi, Spring.

Gems, G. (2009). Understanding American Sports. Routledge.

Gioseffi, D. (1980). Earth Dancing: Mother Nature's Oldest Rite. Stackpole Books.

Kleiman, C. (1973) "Belly Dancing: It May Be More than It's Shaken Up to Be." Chicago Tribune, 21 April 1973, p. 11. Print.

"'Little Egypt' Tells of the Party" (1897). Chicago Daily Tribune, 13 January 1897, p. 4. Print.

"The Myth of Little Egypt" (1942). Chicago Daily Tribune, 07 May 1942, p. 14. Print.

"No More Midway Dancing" (1893). The New York Times, 7 December 1893. Print.

Shay, A. Dancing Across Borders. McFarland \& Company, Inc., 2008.

Shay, A., \& Sellers-Young, B. (2005). Belly Dance: Orientalism, Transnationalism, and Harem Fantasy. Mazda. Print.

Shira (2003). "When Pop Culture Meets Belly Dancing; Here We Go Again!" GildedSerpent.com. 16 June 2003. Retrieved 27 Apr. 2010 from http://www.gildedserpent.com/articles22/shirapopculture.htm

Stanley, T.L. (2004). "Pop Culture: Belly Dancing Slinks into the Mainstream". Advertising Age, 05 January 2004. Retrieved 27 Apr. 2010 from http://adage.com/article?article_id=97259

St. Louis (1904). Louisiana Purchase Exposition, The Greatest of Expositions: Completely Illustrated. St. Louis: Sam'1 F. Myerson Printing Co.

Yates, R. (1971). "Women Wiggle into Trimmer Shape with Belly Dancing". Chicago Tribune, 18 November 1971, p. Print. 
AUTHOR'S ADDRESS:

Ashley M. Popp

2061 Bluemist Drive

Aurora, Illinois, 60504

USA

Email: poppash@gmail.com 